\title{
Reconfiguración del Canon Literario Cubano: Crítica Literaria Contemporánea y Perspectiva de Género en Cuba (1989 - 2012)
}

\author{
Reconfiguration of the Cuban literary \\ canon: Contemporary literary criticism \\ and gender perspective in Cuba \\ (1989 - 2012)
}

\author{
Raiza Rodríguez
}

\section{Resumen}

El trabajo problematiza la relación entre crítica literaria y canon en el campo cultural cubano. Evalúa las intervenciones de la primera genéricamente marcada en la reconfiguración del canon literario nacional. Plantea que la crítica tradicional (patriarcal, hegemónica, autoritaria) cubana se fundamenta en mitos construidos históricamente sobre la literatura de las autoras. Particularmente en los de su presunta precariedad, ahistoricidad e inferioridad, los cuales han sido el argumento para su deliberada discriminación. Asimismo, aquí se estudia el ensayo y la crítica literaria escrita por académicas cubanas (Luisa Campuzano, Nara Araújo, Mirta Yáñez, Susana Montero, Zaida Capote) desde una perspectiva de género conscientemente asumida. De manera que, se ofrece un panorama del desarrollo de dichos estudios en Cuba desde la década del ochenta hasta el 2012.

Palabras claves: crítica literaria, canon, género, patriarcal, mitos.

\section{Abstract}

The work problematizes the relationship between literary criticism and canon in the Cuban cultural field. Evaluates the interventions of literary criticism generically marked in the reconfiguration of the national literary canon. It argues that the traditional Cuban criticism (patriarchal, hegemonic, authoritarian) is based on myths historically constructed about the authors' literature, particularly on those of its alleged precariousness, ahistoricality and inferiority, which have been the argument for its deliberate discrimination. The article studies the essay and literary criticism written by Cuban academics (Luisa Campuzano, Nara Araújo, Mirta Yáñez, Susana Montero, Zaida Capote) from a consciously assumed gender perspective. It offers an overview of the development of gender studies in Cuba from the eighties to 2012.

Key words: literary criticism, canon, genre, patriarchal, myths.

«Una crítica de la crítica debería abordar el estudio sistemático de los diálogos que los críticos emprendieron alguna vez, no sólo con los artistas

y las obras, sino también [...] con la tradición científica, humanista y crítica que les precedió»

Efrén Alexander Geraldo, «La crítica de la crítica...»

\section{Humus Cultural y Exhumación}

La crítica literaria ha sido un dominio exclusivamente masculino y su desarrollo ha estado marcado por un androcentrismo invariable. En la tradición cubana su comportamiento ha sido similar al de otros contextos. Históricamente, estos estudios se han distinguido por una postura androcéntrica y patriarcal. Es decir, por una "visión particular del mundo que se caracteriza por sobregeneralizar la experiencia de los hombres como la experiencia humana per se" (Güereca, 2015, p. 77). Condición tan benéfica como perjudicial, puesto que si bien es cierto que cuanto han concluido es verdad, también lo es el hecho de que es una verdad incompleta, en tanto desconocen - deliberadamente o no- una zona indispensable de la producción literaria nacional: la de las escritoras. La visión sesgada de la mayor parte de nuestra crítica e historiografía literarias pone en tela de juicio la objetividad de sus hallazgos, digamos, su cientificidad. Esta duda razonable ha sido instalada en nuestro contexto por la crítica escrita desde una perspectiva de género ${ }^{1}$ conscientemente asumida, cuyas lecturas han reconfigurado la tradición literaria de la nación cubana.

Buena parte de nuestra crítica literaria tradicional (patriarcal) se ha elaborado sobre presuntas verdades en torno a la literatura de las escritoras. Las mismas, tristemente célebres, se han convertido — por su repetición ad infinitum — en mitos. 
Los cuales han sido heredados a veces inconscientemente, de generación en generación, y su nociva existencia ha deformado nuestra percepción de la realidad literaria. Destruir esos mitos ha resultado una tarea difícil, pero necesaria en la configuración de una historia literaria nacional, no sólo menos discriminatoria, sino más objetiva, científica y realista.

La praxis desmitificadora (Araújo, 1997) de la crítica que evalúa la literatura, y sus procesos, sin discriminar el texto por el sexo de su autor ha revolucionado los estudios literarios (y culturales) en la isla. Su capacidad transformadora es, apenas, incalculable: reconfiguración de nuestra historia literaria (y nacional). Ampliación del canon y del corpus. Nuevas lecturas a obras de escritores consagrados. Democratización de nuestra literatura, al reivindicar géneros hasta entonces considerados menores (especialmente una literatura memorialística como cartas, diarios de viajes, et al). En fin, una historia literaria, cultural y nacional, más heterogénea e inclusiva.

A pesar de las ventajas ofrecidas por el ensayo y la crítica realizados desde esta perspectiva de análisis literario, aún no se han estudiado los mecanismos, así como los métodos mediante los cuales esta praxis interviene los estudios literarios contemporáneos en $\mathrm{Cuba}^{2}$. Nuestro intento por descubrirlos obedece a la certeza de que esta crítica ha sido el antídoto eficaz contra una de las mayores injusticias históricas cometidas en el terreno de lo literario.

Basándose en las tesis de Ángel Rama y Octavio Paz, el crítico e investigador Ambrosio Fornet (2008) —uno de los que más sostenidamente se ha ocupado del estado de la crítica literaria en nuestro contexto- ha reconocido oportunamente el papel fundacional de la crítica, al recordar que: "si bien es cierto que las obras las hacen los autores, la Literatura, con mayúscula la 'hacen' los críticos [...] aquellos que en cada época 'construyen' el canon” (Fornet, 2008, p. 253). De modo que le concede a la figura del crítico el poder que tiene realmente, pues lo considera el lector especializado que puede opinar "como conciencia histórica de la literatura en un momento dado" (Fornet, 2008, p. 118). De su rol protagónico en la configuración del canon y del corpus de las literaturas nacionales ha dado cuenta este teórico cubano, al decir:
Te asombraría saber cuántos autores, poemarios, novelas, libros de cuentos se pierden en el anonimato [...] en el curso de medio siglo. Y de los que logran sobrevivir a través de una cita o de un piadoso comentario en los manuales de literatura... (Fornet, 2008, p. 115).

Fornet define el conjunto de obras y autores que en la humanidad han sido a través de una inmejorable metáfora: humus cultural ${ }^{3}$. A partir de ella, explica la configuración de las literaturas nacionales de la siguiente forma: "De ese humus cultural va surgiendo una norma y un promedio que nos permiten [a los críticos] armar después, por eliminación, lo que conocemos como historia de la literatura" (Fornet, 2008, p. 114; la cursiva es nuestra).

Ahora bien, si la susodicha eliminación se ha fundamentado en mitos construidos y no en realidades concretas y comprobables, como ha sucedido con el discurso literario de las escritoras cubanas, se puede concluir que tal eliminación ha sido no sólo mal intencionada (lo cual es subjetivo) sino muy poco científica y, por esta misma razón, reparable. ¿Reparable? Sí, reparable. ¿Cómo puede repararse tal exclusión? A través de la metodología de la visibilidad de la crítica literaria genéricamente marcada. Esta desarticula los presupuestos ideológicos discriminatorios que han fundamentado las estrategias de ocultamiento desarrolladas por la crítica tradicional para eliminar de las historias (literarias) nacionales el discurso de nuestras escritoras ${ }^{4}$.

En carta del 9 de noviembre de 1952 María Zambrano (1996) felicitaba a Camila Henríquez Ureña por una conferencia donde la cubano-dominicana reparaba el perjuicio cometido contra las mujeres, al reconocer su importancia en el desarrollo de la sociedad. En la misma le comentaba: "Y que bien hace también en exhumar, dar a conocer la historia de [la mujer] en estas tierras [...] no quiero dejar de pedirle que no deje así tema tan importante y lo recoja en su libro" (Henríquez Ureña, 1996, p. 267; las cursivas son nuestras). La elección del verbo exhumar (de ex- y el latín humus 'tierra': desenterrar un cadáver o restos humanos // ruinas, estatuas, monedas, etc.; sacar a la luz lo olvidado) para referirse a la reparación/reivindicación/visibilización de la mujer en la historia de la humanidad es un hallazgo para nosotros, sobre todo a la luz que arroja el concepto de Fornet. 
La tierra como locus donde todo sucede, donde se hace la Literatura, la Historia, la Cultura. El humus, presente en la capa superficial del suelo procedente de la descomposición de todos los elementos, y la exhumación, acción y efecto de desenterrar algo que ha sido sepultado. La crítica androcéntrica ha ocultado todo lo relativo a la mujer (su literatura, su historia, su cultura, su cosmovisión, etc.). Ni siquiera puede encontrársele en la capa superficial del suelo. Para sacarlo a la luz una nueva crítica ha tenido que excavar (quitar la tierra de su alrededor) y asignarle un lugar en el mundo.

\section{Androcentrismo y mitos vs resistencia y visibilidad}

Como se ha hecho mención, históricamente, la mayor parte de los estudios literarios cubanos se ha sustentado en presupuestos ideológicos androcéntricos. Nuestra tradición crítica, básicamente masculina, ha prestado mayor atención a las obras literarias de los escritores, a partir de las cuales ha desarrollado sus tesis, teorías, conceptos y periodizaciones. Luego, sus hallazgos de investigación, basados en un corpus que desconoce la producción de las escritoras, se han generalizado para describir, caracterizar y/o periodizar su creación literaria. Por tal razón, la mayoría de las veces, las obras literarias de las autoras no se ajustan a las generalizaciones preestablecidas por la crítica dominante y han sido descritas estereotipadamente o ajenas a las corrientes literarias y artísticas de su época.

En resumen, la crítica literaria tradicional cubana ha desterrado - conscientemente o no- la literatura de las escritoras del discurso literario nacional, amparada en tres grandes mitos: su presunta precariedad, ahistoricidad $e$ inferioridad.

Precariedad: referido al aspecto cuantitativo de la literatura de las escritoras. Particularmente a su escasez respecto de la de los escritores cuya producción ha sido considerada mayoritaria en los distintos períodos literarios.

Ahistoricidad: referido a la endeble relación de la literatura de las escritoras con los asuntos públicos de la nación: históricos, políticos, et al.

Inferioridad: referido al aspecto cualitativo de la literatura de las escritoras. Particularmente a su baja calidad respecto de la de los escritores cuya producción ha sido evaluada, según la escala de valores de la crítica androcéntrica, artísticamente superior.

La gran contribución de la crítica literaria genéricamente marcada en nuestro entorno ha sido desterrar el androcentrismo arraigado en los estudios literarios cubanos durante siglos (Montero 2008, Hernández Hormilla, 2011). A partir de la década del ochenta, las ensayistas y críticas de la isla comenzaron a derrumbar los mitos sobre los cuales había descansado impunemente la exclusión de nuestras escritoras. Han reparado/recuperado su contribución real a la historia literaria de la nación. Esa escritura reflexiva ha resultado un acto de resistencia. Las voces de cinco académicas se destacan del conjunto: Luisa Campuzano (1943), Nara Araújo (1945-2009), Mirta Yáñez (1947), Susana Montero (1952-2004) y Zaida Capote (1967) ${ }^{5}$. Por la desatención que esta praxis ha sufrido, a pesar de su innegable aporte al desarrollo de los estudios literarios y culturales en el contexto académico cubano, este trabajo pretende evaluar su papel en la (re)configuración de los estudios literarios cubanos. Igualmente, identificar sus principales líneas de investigación/temáticas. Tanto como descubrir sus modos/métodos para destruir los mitos androcéntricos, a partir del análisis de algunos textos representativos (publicados en volúmenes) de esta vertiente de nuestra crítica contemporánea.

\section{Canon Literario, Crítica Literaria $Y$ Perspectiva De Género En Cuba}

«Yo no sé cuál ha de ser en último término la contribución máxima de la mujer a la nueva vida de la humanidad, pero su actuación pública a lo largo del tiempo tendrá que afectar las raíces espirituales de la organización social»

Camila Henríquez Ureña, «Feminismo»

Durante el segundo lustro de la década del ochenta del pasado siglo, los estudios literarios cubanos entraron en contacto con las teorías de género, previamente desarrolladas en Norteamérica, Francia y Latinoamérica donde se habían complejizado, al interactuar con los conceptos de raza, etnia, colonialismo y subdesarrollo. Por las peculiaridades de nuestro contexto político, económico y cultural la teoría literaria feminista y su crítica arribaron tardíamente al campo intelectual y ámbito académico cubanos. 
Su impronta se produjo durante el llamado período de Rectificación, el cual obró como impulso de una concientización para las mujeres escritoras/pensadoras (Vallejo, 2012). La estadounidense Catharina Vallejo (2012) ha indicado que "no es sino después de ese momento que se comienzan a hacer las revisiones, los cambios, las 'rectificaciones' de las perspectivas hacia la mujer que en otras partes de Occidente se habían iniciado décadas antes" (Vallejo, 2012, p. 523). El interés de la crítica literaria cubana por la literatura de las escritoras no fue un suceso aislado, nació en el contexto de una oleada de interés por la escritura de las mujeres que se produjo durante las décadas setenta y ochenta del siglo pasado, paralelamente en el ámbito norteamericano y francés (Moi, 2019). Toril Moi (2019) señaló como principal detonante de tal interés por la escritura y el universo femeninos las posturas androcéntricas predominantes "más que de costumbre" en la comunidad literaria de aquellos contextos (Moi, 2019, p. 94). En Cuba el surgimiento de la crítica literaria feminista también está asociado a la exacerbación de las posiciones androcéntricas y misóginas extremistas: la isla vivió una situación similar durante las dos primeras décadas posrevolucionarias, especialmente durante los cinco años comprendidos entre 1971-1976, bautizados por el crítico Ambrosio Fornet (2007) como 'quinquenio gris'. Durante este periodo lo masculino $-\mathrm{y}$ todo lo que a ello se asocia: la violencia, lo público, el centro(pre)dominó (en) el campo literario cubano.

También los vínculos intelectuales entre las académicas cubanas y mexicanas, especialmente con Elena Urrutia y Jean Franco, notables exponentes de los estudios literarios feministas en Latinoamérica, catalizaron la introducción de los estudios de género en Cuba. ${ }^{6}$

Estos impulsos externos, unidos al clima de apertura que distinguió la 'Rectificación' de los ochenta y el relajamiento de las estructuras patriarcales durante la profunda crisis en la que se sumergió nuestro país debido a la caída del Campo Socialista y la consiguiente desaparición de la URSS ${ }^{7}$, posibilitaron la introducción de las teorías de género en la academia cubana, digamos, sin sobresaltos. ${ }^{8}$

La irrupción de tales teorizaciones en la isla, donde también el feminismo del siglo xx había tenido amplio arraigo, produjo una revolución epistemológica en las ciencias sociales y, particularmente, en la crítica e investigación literarias. Nuestro contexto se transformó en diferentes niveles y se gestó un panorama más favorable para el desarrollo de las escritoras cubanas. Con el propósito de divulgar su creación literaria y su pensamiento, se crearon tanto cátedras y programas de estudio de la mujer/de género, como nuevas colecciones editoriales. Se impartieron cursos y talleres. Tuvieron lugar congresos, eventos, concursos, etc. ${ }^{9}$ No obstante, la mayor repercusión de la epistemología feminista fue, sin dudas, el renacer ${ }^{10}$ y ulterior desarrollo de una crítica literaria cuyo objeto fue la literatura de las escritoras cubanas/foráneas, hasta entonces ausentes o con una presencia relativa en el discurso literario de la nación.

La crítica literaria escrita en la isla desde una perspectiva de género se comportó similar a la de otros contextos. Al principio sus objetivos se concentraron en rescatar - y releer - las escritoras del pasado. Progresivamente se ampliaron y se fijaron en la necesidad de "descentralizar una perspectiva de análisis androcéntrica en la literatura, establecida por un canon literario masculino, blanco y heterosexual" (Hernández Hormilla, 2011, p. 54) y continuaron evolucionando hasta el punto de considerar lo femenino una categoría no exclusiva de la literatura de mujeres, sino un poderoso instrumento de análisis, capaz de desmontar las oposiciones binarias sobre las cuales se ha estructurado la cultura occidental (Araújo, 1997).

Sin despreciar otras posibilidades interpretativas, o combinándolas en un eclecticismo creativo, una zona de nuestra crítica asumió la perspectiva de género como una teoría de lectura válida y la convirtió en punto de partida medular para la exégesis del texto literario. En ella encontró un potencial desmitificador, idóneo para estudiar la literatura en tanto creación como en su 'organización', entiéndase la crítica y la historiografía anteriores.

Esta crítica literaria tuvo un momento de esplendor creativo durante las dos últimas décadas del pasado siglo y la primera del que transcurre, cuando alcanzó un auge editorial sin precedentes. Sin embargo, ya desde mediados de los ochenta se avizoraba un cambio de sensibilidad crítica, pues en esa época: 
empieza a surgir una concientización genérica entre las ensayistas, proceso que quiere revisar [el] pasado de silencio [...] en una búsqueda por construir un futuro para las mujeres cubanas en consonancia con el mundo occidental [...], desde perspectivas teóricas actuales sobre cultura y género (Vallejo, 2012, pp. 528-529).

En estos años se publican los volúmenes Nueva visión de Dulce María Borrero (1983) de Yolanda Ricardo sobre "una de las feministas más consecuentes del siglo XX cubano"11. Las antologías genéricamente marcadas, Viajeras al Caribe (1983) de Nara Araújo y Las mujeres y el sentido del humor (1986), donde la escritora Olga Fernández compiló la obra de catorce narradoras cubanas. Tanto su criterio de selección como su comentario crítico indican la incipiente pero genuina conciencia de género entre las escritoras de la isla.

Durante el segundo lustro de esta misma década se comienza a producir en Cuba un discurso reflexivo, interesado en tematizar y periodizar la literatura de las escritoras cubanas. Es el caso de: "La mujer en la narrativa de la Revolución" (1984) de Luisa Campuzano y las investigaciones de Susana Montero sobre La narrativa femenina cubana 1923-1958 (1989) y la Obra poética de Mirta Aguirre (1987). ${ }^{12}$

La mayor parte de la crítica producida en la isla durante la década de los ochenta sobre el tema mujer y literatura estuvo desprovista del andamiaje teórico-metodológico propio de los estudios de género (Araújo, 1997, p. 9), ya ampliamente desarrollado en otros contextos académicos, como el norteamericano y europeo. Sin embargo, los resultados de tales investigaciones tuvieron gran significación: además de establecer sólidas bases para el desarrollo de esta crítica durante las siguientes tres décadas, demostraron el agotamiento epistemológico de la crítica tradicional cubana. El comportamiento de esta, especialmente durante las dos primeras décadas del período revolucionario, había estado marcado por un androcentrismo exacerbado que le impedía evaluar objetivamente la literatura y la cultura, al desterrar de ellas cuanto se apartara de la visión dominante, básicamente masculina.

Sin embargo, fue en los noventa cuando esta crítica: "comenzó a ganar un lugar en los medios de difusión cultural y espacios académicos, avances que no podrían desligarse de un cambio en la percepción sobre el feminismo y los estudios de género en las instituciones relacionadas con la investigación sobre la mujer en Cuba" (Araújo, 1997, p. 9). Inicialmente, se publicó en las principales revistas literarias y culturales del país, las cuales dedicaron números especiales a la creación de las mujeres. Para 1995, Nara Araújo realiza un balance sobre el estado de esta crítica en la isla donde menciona los ensayos más representativos publicados hasta la fecha: "El alfiler y la mariposa" de su propia autoría. "Estudio de la narrativa femenina cubana en las revistas santiagueras (1933-1958)" de Aida Bahr. "Las muchachas de La Habana no tienen temor de Dios", "Cuba 1961: los textos narrativos de las alfabetizadoras" y "Últimos textos de una autora: crónica y memorias de Dulce María Loynaz" de Luisa Campuzano. Asimismo, "Del discurso en sí al discurso para sí". "La expresión femenina en el periodismo. Estrategias y propuestas de un periodismo marginal" y La narrativa femenina cubana 1923-1958, de Susana Montero.

A finales de esta década vieron la luz dos volúmenes fundamentales para comprender la evolución de los estudios de género en el contexto cubano: El alfiler y la mariposa de Nara Araújo y Con el lente oblicuo. Aproximaciones cubanas a los estudios de género (1999), preparada a cuatro manos por Susana Montero y Zaida Capote. Publicados a las puertas del siglo XXI, significaron la apertura de la crítica literaria y cultural de la isla a una nueva forma, nunca antes ensayada, de asomarse a los problemas de la sociedad y su cultura. El primero demostró la utilidad de esta crítica literaria, al reconocer en el género una categoría de análisis de dimensiones insospechadas al relacionarla con el poder. Sus múltiples líneas de investigación se mueven entre el estudio de las llamadas literaturas íntimas (autobiografías, escritura de viajes), la lectura de la obra literaria de escritoras consagradas y las interrelaciones entre las coordenadas de raza y género. A lo largo de sus páginas, su autora reconoce los fundamentos androcéntricos imperantes en el estudio (y la enseñanza) de nuestra tradición literaria y considera entre los objetivos fundamentales de su libro "cubrir el vacío en la lectura de textos no estudiados, (por privilegiarse los de los hombres), y ejercitar el análisis desde la perspectiva del género" (Araújo, 1997, p. 8). En él ofrece, 
además, especial atención a las relaciones de la literatura de las autoras con la tradición literaria (mayoritariamente masculina) puesto que considera «indispensable» leer a los autores para establecer el modelo del que aquella difiere, ya que "ninguna palabra se lanza en el vacío, ninguna palabra es neutra”, siempre establece un diálogo con la que la precede (Araújo, 1997, p. 15). Su análisis literario, transversalizado por una actitud consciente del género, propone una lectura alternativa de los textos y sus contextos, la cual revela aspectos novedosos, hasta entonces inadvertidos por la crítica literaria dominante. La ensayista demuestra un dominio de las teorías de género más contemporáneas y una presencia notable de los conceptos y categorías propuestos por el feminismo literario francés, particularmente por las teóricas Hèléne Cixous, Julia Kristeva y Luce Irigaray.

Nara Araújo es, de las estudiadas, la autora más cercana a las posturas del feminismo europeo. Su discurso reflexivo, no obstante, logra evadir el esencialismo y las posturas biologicistas que, en ocasiones, distinguieron las teorizaciones de las francesas. Su crítica literaria tiene puntos de contacto con enfoques teóricos como el deconstructivista, pues ambos se empeñan en desestabilizar los discursos hegemónicos y monológicos. Su epicentro lo constituyen a la par dos categorías fundamentales: género y poder.

La rápida comprensión de la relación entre el género y el poder por parte de la crítica literaria escrita en Cuba desde una posición consciente de género permitió a sus defensoras avanzar a otro nivel más complejo de interpretación de la literatura, la cultura, los procesos y sus contextos. Con este paso, las posibilidades interpretativas de la crítica literaria cubana contemporánea se expanden hasta lugares insospechados. La autora considera:

que la capacidad de esta crítica para leer cualquier texto, de autoría masculina o femenina, de cualquier latitud, proviene de la comprensión de que, más allá de la manera en que se construyen las imágenes de las mujeres, el poder se ejerce de manera análoga a las relaciones de género (Araújo, 1997, p.11; el subrayado es nuestro).

Esta crítica no debe:

solamente [...] leer a las escritoras para (re)descubrirlas y promoverlas, sino de preguntarse de qué manera el poder se ejerce o se tolera, se sufre o se transgrede, en el espacio textual. Poder como organización de jerarquías, subordinación de 'lo débil' a 'lo fuerte' (Araújo, 1997, p.11; el subrayado es nuestro).

Esta forma de entender el tema nos lleva a concluir que una lectura de género está lejos de ser una lectura esquemática o reduccionista. Dado que puede aplicarse a todos los textos literarios porque, aunque importe quién escribe y desde que posición lo haga, "el juego del poder no siempre se corresponde con las expectativas del sexo. Lo masculino y lo femenino entonces, adquieren cierta autonomía de la entidad 'autor/a real"' (Araújo, 1997, pp.11-12; el subrayado es nuestro).

Con el lente oblicuo..., por su parte, midió la temperatura, así como el estado de los estudios de género en Cuba justo antes de finalizar el siglo xx. Demostró el interés que tales teorías habían despertado en los especialistas cubanos de distintas ramas de las ciencias sociales, atraídos por las posibilidades interpretativas que ofrecían. Reunió los trabajos más sobresalientes escritos desde esta perspectiva hasta entonces en nuestro país: dieciocho textos sobre literatura (cubana e iberoamericana), artes pláticas, teatro, cine y ciencias políticas. Tiene no pocos méritos como obra colectiva, en particular la voluntad solidaria y democrática de sus compiladoras quienes reunieron colegas de variadas ramas del conocimiento, así como del sexo masculino (los investigadores Amir Valle y Víctor Fowler). En él se publicaron los ensayos de las autoras más representativas de esta crítica en nuestro contexto, los cuales adelantaban algunas de las principales líneas de investigación que se desarrollarían durante la primera década del siglo XXI.

En este período, además, se publica Aproximaciones a los estudios de género... (1997), de Yanetsy Pino Reina, el cual tiene una significación particular en el desarrollo de los estudios de género en la isla, especialmente por su vocación teórica. Su autora estudia la repercusión de la teoría feminista y su crítica en el contexto cubano y ofrece un breve panorama de su desarrollo en Cuba.

Con la entrada del siglo XXI, la crítica literaria cubana contemporánea que había encontrado su propia forma de ensayar la literatura desde una perspectiva que reconocía la igualdad creativa de la mujer vivió su época de esplendor. Durante 
los primeros doce años se publicaron en la isla títulos representativos: Cubanas a capítulo (2000), Diálogos en el umbral (2003); La cara oculta de la identidad nacional (2003); Las Muchachas de La Habana no tienen temor de Dios (2004); La Avellaneda bajo sospecha (2005); Contra el silencio (2005); La nación íntima (2008) у Cubanas a capítulo. Segunda temporada (2012), entre otros. En este recorrido se desarrollaron varias líneas de investigación. Una de las primeras, y más sobresalientes a la vez, es la revisión y relectura de la obra literaria de escritoras cubanas consagradas, como Gertrudis Gómez de Avellaneda y Dulce María Loynaz ${ }^{13}$. Representativos de esta línea de trabajo son los volúmenes de Susana Montero y Zaida Capote dedicados por completo a la vida y obra de tales escritoras, $L a$ Avellaneda bajo sospecha (2005) y Contra el silencio (2005), respectivamente. Además, se han estudiado diversos aspectos de la vida y obra de autoras cubanas no menos notables, como Aurelia Castillo de González (Yáñez, 2000; Campuzano, 2004) ${ }^{14}$; Ofelia Rodríguez Acosta (Capote 2008); Camila Henríquez Ureña (Yáñez, 2003; Capote, 2008); René Méndez Capote (Capote 2008), entre otras.

Esta línea temática estuvo vinculada estrechamente con la necesidad de construir una tradición literaria donde las escritoras de la isla se reconocieran y encontraran paradigmas de escritura. En "Las muchachas de La Habana no tienen temor de Dios..." (Campuzano, 2004) dedicado a la Marqueza Jústiz de Santa Ana, la "primera escritora cubana, poco o nada conocida en Cuba" (Campuzano, 2004, p. 13), Luisa Campuzano revela aspectos concernientes al origen de la literatura cubana escrita por mujeres.

Otra zona de esta crítica ha prestado particular atención a los vínculos entre género sexual y género literario. En un grupo importante de ensayos se ha estudiado la literatura memorialística de las escritoras cubanas, tales como autobiografías, relatos de viajes y confesionales, hasta entonces prácticamente ignorados por el discurso crítico e historiográfico dominantes. Nara Araújo y Zaida Capote escribieron importantes ensayos teóricos dedicados a descubrir la peculiar relación de las escritoras con los géneros autobiográficos Es el caso de: "La autobiografía femenina ¿un género diferente?" y "Vidas de Mujeres. Biografía y relaciones de género", respectivamente. La primera estudió la escritu- ra de viaje femenina del siglo XIX en "Verdad, poder y saber. Escritura de viajes femenina" y en "Otra vez, Viajeras al Caribe", y la segunda, el discurso autobiográfico cubano en "Memoria familiar/memoria nacional. El "caso" Lola María" e "Identidad y nación. Memorias de una cubanita que nació con el siglo". Además, son ilustrativos los primeros tres epígrafes de su volumen La nación íntima: "Autobiografía y relaciones de género", "Entre la verdad y la incertidumbre. Autobiografía y relaciones de poder entre los géneros" y "De Narciso y el espejo: autobiografía, psicoanálisis y género".

Paulatinamente, esta crítica asumió nuevas tareas y amplió sus intereses. Se publicaron ensayos cuyos objetivos fueron describir las principales tendencias de la literatura de las autoras: sus géneros privilegiados y estrategias discursivas más recurrentes. Examinar las tensiones de esa literatura con las distintas manifestaciones del poder, político y/o literario (canon, instituciones, historias y antologías literarias). Enumerar las multifactoriales causas de su posición desventajosa con respecto a la literatura de los autores, y estudiar la imagen y la representación de la mujer en ella, así como sus consecuencias en la modelación de los sujetos nacionales.

En este sentido esta praxis reflexiva resultó reveladora, al descubrir el sustrato androcéntrico que dominaba las relaciones de la literatura de las escritoras con el poder. Las ensayistas de la isla interrogaron las estructuras y prácticas de autoridad. Analizaron la escasa presencia (o la presencia relativa) de las obras de las escritoras en las antologías e historias literarias por el peso que ambas tienen en la conformación del canon de las literaturas nacionales, y denunciaron la eliminación de la visión de las escritoras cubanas del discurso literario nacional. Algunos de los ensayos más ilustrativos de esta tendencia son "La doncella y el minotauro", "Cuba, años sesenta. Cuentística femenina y canon literario" y "La doncella y el minotauro. Otra vez sobre la cuentística femenina de la Revolución" (Capote, 2008).

La interrelación entre los conceptos de género, identidad y nación constituyeron otra línea de investigación fundamental desarrollada por esta crítica literaria en nuestro contexto. Algunos ensayos demostraron cuán imperativo era reconsiderar nuestra nacionalidad - su proceso de formación y consolidación- sobre la plata- 
forma teórica de la perspectiva de género. Las investigadoras se replantearon la historia literaria del país y estudiaron la imagen de la mujer en las obras literarias, tanto de los autores como de las autoras, lo cual desbrozó el camino para análisis más complejos sobre la conformación del imaginario nacional. El entrecruzamiento de distintas categorías de análisis — género, identidad y nación- dio como resultado la modelación de una imagen nueva, inusitada -inclusiva, proteica y heterogénea- del sujeto y la nación cubanos. En La cara oculta de la identidad nacional y La nación íntima tales conceptos se entretejen en un discurso crítico-literario que destruye la imagen unívoca, monolítica, de nuestra nacionalidad construida por la crítica tradicional (patriarcal).

Durante el período, este discurso crítico se ocupó fundamentalmente de la narrativa y la poesía de las escritoras, y atendió menos el teatro y el ensayo. La lírica de las autoras fue estudiada, entre otras, por Mirta Yáñez quien dedicó diferentes ensayos al tema: "Poetisas sí" y "Aurelia Castillo, y otras voces en torno al 98" (Yáñez, 2000). Sin embargo, fue el género narrativo el que recibió mayor atención pues: "la aparición de diversos ensayos y estudios monográficos sobre la narrativa femenina cubana anterior y posterior a 1959, constituyeron los signos más evidentes de[1] [su] renacer" (Araújo, 1997). Este resurgir estuvo vinculado al auge y desarrollo sin precedentes de la producción textual de las narradoras cubanas durante la década del noventa. El trabajo de Luisa Campuzano sobre la narrativa de las escritoras durante el período revolucionario, así como el de Susana Montero sobre la de las autoras cubanas del republicano abrieron una línea de trabajo importante: se produjeron y publicaron notables ensayos sobre esta temática cuyos objetivos fueron caracterizar, interpretar y valorar el discurso narrativo de las escritoras de la isla. Se destacan sobremanera en esta temática los ensayos de Mirta Yáñez: "Y entonces la mujer de Lot miró...”, "Ruidos y cuartos propios" (Yáñez 2000), "Narradoras cubanas: identidades al borde del ataque de nervios", "Feminismo y compromiso. Ambigüedades y desafíos en las narradoras cubanas" (Yáñez 2012). También los trabajos de Luisa Campuzano quien sistematizó los temas recurrentes en los textos de nuestras narradoras en "Literatura de mujeres y cambio social: narradoras cubanas de hoy" y de
Nara Araújo quien estudió el corpus, atendiendo a distintos aspectos de la creación en "El espacio otro en la escritura de las (novísimas) narradoras cubanas", "Más allá de un cuarto propio: once novelas en pugna en el siglo XXI" y "Zonas de contacto: narrativa femenina de la diáspora y de la isla de Cuba".

Esta crítica literaria desarrolló, por otra parte, un discurso metacrítico interesado en defender la capacidad interpretativa de la teoría literaria feminista y su crítica, así como la utilidad de la perspectiva de género para develar nuevos aspectos de la literatura, la cultura y la sociedad cubanas. En un grupo de ensayos se expusieron sus logros, propósitos, ventajas, alcance metodológico y poder desmitificador. No obstante, nuestras ensayistas advirtieron el riesgo de caer en simplificaciones biologicistas, propias de posiciones fundamentalistas y reduccionistas (Yáñez, 2012), al restringir el debate sobre literatura exclusivamente al tema de género. Nara Araújo y Mirta Yáñez defendieron de manera particular las bondades tanto como las utilidades de esta crítica literaria en algunos trabajos. La primera concentró la mayoría de sus teorizaciones sobre el tema en algunos ensayos específicos - " $\mathrm{Li}$ teratura femenina, feminismo y crítica literaria feminista en Cuba"; "La escritura femenina y la crítica feminista en el Caribe: otro espacio de la identidad" (Yáñez, 1996), "Repensando desde el feminismo los estudios latinoamericanos" (Araújo, 2003), "Primeras palabras" (Araújo, 1997)—. Mientras la segunda las esparció por sus numerosos ensayos, aunque una parte considerable de ellas se pueden encontrar en un texto que bien pudiera considerarse su Ars poética, conformado por fragmentos de entrevistas concedidas por la autora a estudiosas del tema: "A mí misma; todo fundamentalismo es anti intelectual” (Yáñez, 2012). ${ }^{15}$

Como puede advertirse, la crítica literaria cubana contemporánea escrita desde la perspectiva de género se caracteriza por su diversidad temática, la cual constituye uno de sus rasgos distintivos y un síntoma de su fortaleza ${ }^{16}$. No obstante, a pesar de la heterogeneidad de sus propuestas críticas, las ensayistas cubanas comparten su preocupación por las mujeres como escritoras, lectoras y objetos de la representación (Golubov, 2012, p. 22). Poseen una preocupación (objeto), estrategia (método) y propósito (objetivo) comunes: estudiar la relación mujer-literatura desde 
una perspectiva que reconoce la igualdad creativa e intelectual de la mujer, con el fin de desarticular la ideología androcéntrica que ha (pre) dominado (en) nuestra cultura durante siglos, provocando la eliminación (deliberada o no) de la obra de las escritoras de la tradición literaria nacional.

Con objetivos y propósitos diferentes a los de la crítica literaria tradicional/dominante, ha visibilizado el aporte de las escritoras a la literatura, cultura e identidad nacionales. Al centrar su atención en la mujer como emisora, receptora o personaje de la literatura, ha estudiado nuestra historia literaria y la foránea desde un nuevo punto de vista. En su desarrollo se aprecia una evolución teórica, notable en un aumento del dominio del instrumental teórico propio de los estudios de género, así como en la ampliación de sus objetos de estudio, propósitos y campo de acción, de lo meramente literario a la complejidad epistemológica de una crítica con una elevada capacidad para replantearse no sólo el canon literario, sino la modelación de la identidad de la nación y de los sujetos nacionales.

\section{La Refutación De Los Mitos. De La Teoría A La Praxis}

«No es de exclusivo uso de las mujeres la crítica feminista, [...] una actitud consciente del género potencia a cualquier lector/a. Contrariamente a lo que a veces se piensa, una lectura de género abre nuevos horizontes a la voz y la escritura»

¿Cómo el ensayo y la crítica literaria escritos desde una consciencia genéricamente marcada interpelan al tiempo que intervienen la tradición crítica e historiográfica cubana? ¿Cómo impugnan los principales mitos sobre los que ha descansado históricamente la eliminación de las escritoras cubanas de nuestra historia literaria y cultural? Un análisis de tres volúmenes representativos ${ }^{17}$ de esta praxis crítica en nuestro contexto intenta responder tales interrogantes.

\section{A propósito de Cubanas a capítulo (2000) /cubanas a capítulo. Segunda temporada (2012) de Mirta Yáñez ${ }^{18}$}

El pensamiento crítico de Mirta Yáñez (1947) ${ }^{19}$ contenido en los dos volúmenes de Cubanas... socava los pilares esenciales en los que se ha fundamentado históricamente la crítica e historiografía literarias cubanas para excluir la literatura de las autoras del discurso literario nacional ${ }^{20}$. La ensayista demuestra que los mitos - precariedad, ahistoricidad, inferioridad - conferidos a la producción de las autoras, carecen de veracidad y que, en realidad, han sido elaborados o amplificados, como las modernas fake news, para desautorizar convenientemente la creación de las escritoras. A partir del estudio de la tradición literaria de las mujeres cubanas y de la huella de la ideología patriarcal en la configuración del sujeto femenino, desarticula los parámetros evaluativos y el sustrato ideológico de nuestra crítica androcéntrica. Le asesta un golpe mortal, al desenmascarar sus estrategias de ocultación, cuando se trata de (re)presentar la escritura femenina en la tradición literaria nacional. La ensayista, no obstante, no se limita exclusivamente a destruir las falsas creencias elaboradas sobre la literatura de las autoras. Aún más, sobre sus ruinas construye una nueva tradición literaria que contempla la voz, la escritura y el pensamiento de las escritoras cubanas de todos los tiempos. Su prosa reflexiva desarticula el sustrato ideológico patriarcal en el plano del contenido y en el de la expresión. El estudio del segundo y de su probable vinculación con aquel pudiera ampliar estas reflexiones en el futuro. La transgresión, la experimentación con el lenguaje, el humor y la contaminación genérica desestabilizan la forma tradicional del ensayo 'académico' en un acto de resistencia tal que excede el plano del contenido.

En sus ensayos destruye el mito sobre la precariedad, al desmentir el manido y falsario expediente de que en Cuba no ha habido escritoras (Yáñez, 2012, pp. 61-62; el subrayado es nuestro), sostenido por buena parte de los estudios literarios para perpetrar su exclusión. Ejemplo de ello son: "Poetisas sí" y "Y entonces la mujer de Lot miró...”. En ambos la investigadora acopia un registro significativo de autoras y obras (narrativas y poéticas). Periodiza, evalúa y jerarquiza una profusa producción literaria, cuya mera existencia pone en crisis la tesis sobre la indigencia de la literatura de las escritoras en diferentes períodos de nuestra historia literaria.

Una parte considerable de los críticos cubanos ha generalizado la falsa idea de que la creación de nuestras escritoras es ahistórica por naturaleza. Ha insistido en que sus obras están enajenadas del acontecer histórico, político e ideológico de su tiempo. Este argumento ha sido la antesala para afirmar que sus tópicos se reducen al 
tema amoroso y los asuntos íntimos, rasgo que han vinculado directamente con la presunta inferioridad de sus obras literarias. En el ensayo dedicado a la poesía de las cubanas escrita a fines del siglo XIX y a la peculiar voz poética de Aurelia Castillo de González, "El discurso femenino finisecular en Cuba: Aurelia Castillo y otras voces en torno al 98", la autora destruye este "falso presupuesto acerca de la atemporalidad de la creación y el pensamiento femeninos, tradicionalmente analizados por la historiografía literaria como desgajados del acontecer social" (Montero en Yáñez, 2000, p. 10), y afirma que en realidad "lo que existe es una permanente vinculación con su tiempo, un registro testimonial y una historia viva y continua dentro del corpus poético cubano" (Yáñez, 2000, p. 179). Reconoce que, aunque buena parte de la poesía escrita por las mujeres durante la etapa fue de corte intimista, "las poetisas sumaron su canto a la poesía patriótica, y, al igual que el resto de los escritores, se unieron al rechazo y desconcierto general ante su época" (Yáñez, 2000, p. 165). Su rechazo al "falso presupuesto" de la ahistoricidad de la literatura femenina se manifiesta en la sólida y argumentada defensa de su tesis, y en la exigencia explícita: "es hora de erradicar de una vez y por todas el gastado cliché de una poesía femenina atemporal, ahistórica y circunscrita a la pasión amorosa" (Yáñez, 2000, p. 165).

La crítica e historiografía cubanas han insistido en sobredimensionar la inferioridad de las creaciones de las autoras. Aunque esa inferioridad tuviera un componente real, ha indicado Yánez, este ha sido amplificado con la intención de minimizar convenientemente su participación en el imaginario de la nación cubana. Así, en "Ruidos y cuartos propios" (Yáñez, 2000), dedicado al discurso narrativo femenino contemporáneo, la ensayista desarticula esta amplificación de la inferioridad, al argumentar la supremacía de las narradoras cubanas en el proceso de consolidación de las principales tendencias narrativas (Montero en Yáñez, 2000, p. 16). Por ejemplo: Lydia Cabrera "dentro de la recreación de los mitos de la tradición afrocubana", Dora Alonso "dentro del criollismo" y Dulce María Loynaz "dentro del ámbito fantástico, experimental y filosófico" (Yáñez, 2000, p. 190). El cual hecho, sin embargo, como ha señalado Susana Montero, ha pasado inadvertido por críticos e historiadores de la literatura cubana (Montero en Yáñez, 2000, p. 16).
Durante la década del noventa, como se sabe, la transformación del contexto literario, político, económico y social cubano propició el acceso más equitativo de las mujeres a la cultura. Esta apertura fue aprovechada por las escritoras para producir un corpus que emula en calidad y cantidad con la de los autores. El hecho confirmó que la precariedad histórica atribuida a la literatura de las escritoras tiene una correlación directa con el problema del acceso de las mujeres a la literatura (congresos, jurados, colecciones editoriales, etc.) que se traduce en la oportunidad real de escribir y publicar. La ensayista estudia la obra de las narradoras cubanas contemporáneas en "Narradoras cubanas: identidades al borde del ataque de nervios" y "Feminismo y compromiso. Ambigüedades y desafíos en las narradoras cubanas" (Yáñez, 2012) y advierte que comparte con la de sus contemporáneos, no sólo el espíritu de su época, sino también los temas, retos y desafíos.

\section{El caso de La nación íntima (2008) de Zaida Capote Cruz}

En La nación íntima (2008) Zaida Capote Cruz (1967) ${ }^{21}$ impugna los presupuestos ideológicos androcéntricos y patriarcales que han sustentado históricamente la mayor parte de los estudios literarios cubanos. La ensayista establece un diálogo bidireccional, en primer lugar, con las obras y sus autoras/es y, en segundo, con la tradición crítica que la precede. Como indica su título, el volumen es representativo de una de las principales líneas de investigación desarrolladas por la crítica literaria genéricamente marcada en nuestro contexto: la que indaga sobre los problemas de la identidad nacional, desde un análisis que privilegia la categoría género.

La autora expresa que el propósito fundamental de su libro es abordar "la presencia de las mujeres en el proyecto nacional, del modo en que negocian su identidad en la historia y la representación de la nación cubana" (Capote, 2008, p. 6; las cursivas son nuestras). En este enunciado se trasluce la actitud desmitificadora de sus páginas donde se minarán definitivamente los mitos y leyendas construidos en torno a nuestras escritoras y sus obras. Al declarar que se ocupará de "la presencia" de las mujeres en el proyecto nacional y de su participación en "la historia" de la nación, la ensayista parte del hecho de que ellas - las mujeres/las escritoras- (sí) han participa- 
do en el proyecto nacional y (sí) han intervenido la historia de nuestra nación. Desde el planteamiento del objetivo fundamental del libro se socavan los mitos referidos, por una parte, a la escasa presencia de las escritoras y, por otra, a la endeble relación de sus obras con los asuntos históricos/públicos de la nación: precariedad y ahistoricidad. De lo que versará el libro será de la tipicidad de la presencia de las mujeres en los asuntos nacionales y de su relación con los asuntos históricos de Cuba. También afirma que abordará la forma en que ellas "negocian" su identidad en "la historia y la representación de la nación cubana”. La elección del verbo negociar - "tratar por la vía diplomática, de potencia a potencia, un asunto, como un tratado de alianza, de comercio, etc."- describe el tipo de relación de las mujeres/escritoras cubanas con "la historia" y "la representación", a saber, una relación donde se desempeñan como sujetos activos. Su enunciado destruye la idea preconcebida sobre la pasividad e inferioridad de las mujeres/escritoras y sus obras, puesto que la acción de negociar implica una participación activa de las dos partes implicadas en el asunto. No la imposición unilateral de la voluntad de una de ellas. Así pues, el volumen reconstruirá la historicidad de las obras de las escritoras cubanas, revelará los lazos entre la historia y su literatura, descubrirá cómo las mujeres/escritoras cubanas han intervenido en la configuración de nuestra historia/ identidad/representación nacionales.

En la primera parte del libro - "La nación íntima" - la autora estudia el discurso autobiográfico femenino cubano. Como antesala, una disertación teórica sobre la autobiografía escrita por mujeres donde se esclarecen asuntos concernientes a la relación entre género sexual y género literario. En particular analiza tres obras representativas de esa tradición literaria: Memorias de Lola María, Memorias de una cubanita que nació con el siglo y Reyita, sencillamente, de Dolores María Ximeno y Cruz, Renée Méndez Capote y Daisy Rubiera Castillo, respectivamente. Sus disertaciones nos revelan cómo los textos de las escritoras cubanas participan en la configuración de nuestra identidad nacional y cómo esos aportes fueron soslayados históricamente por una crítica e historiografía literarias nutridas por la ideología discriminatoria del patriarcado.

Tradicionalmente la mayoría de los estudios literarios de la isla no contemplaron el discurso autobiográfico de las escritoras cubanas - contenido en cartas, memorias, diarios, diarios de viaje, etc. - - La exclusión de la visión de nuestras autoras sobre los asuntos de Cuba trajo como consecuencia la mutilación de una parte indispensable del tríptico historia/identidad/representación nacionales. Según la escala de valores establecida por la crítica tradicional/hegemónica, los textos autobiográficos de las autoras no se consideraron 'literatura' pues no se 'ajustaban' al modelo cultivado/defendido por los autores. Esa percepción — subjetiva- se fundamentó básicamente en el mito de la inferioridad asociado a las mujeres/las escritoras/ y sus textos. La pertinencia de una autobiografía, como se sabe, radica en la existencia de una vida 'digna' de ser contada por su participación en sucesos de interés de diversa naturaleza. Según la ideología dominante, la vida de las mujeres/escritoras sería menos 'digna' de ser contada pues sus asuntos privados/ domésticos le resultaban menos prestigiosos e interesantes: la formación modélica del sujeto nacional no incluía la imagen sensible, frágil, y débil que el pensamiento patriarcal adjudicaba al llamado sexo débil, por lo que las voces de las mujeres fueron proscritas de los discursos que han delineado el proyecto nacional cubano.

Al estudiar el discurso autobiográfico de las escritoras cubanas desde una perspectiva de análisis que pondera el género, la investigadora no solo refuta la presunta inferioridad de los textos pertenecientes a esta tradición literaria que, a la misma vez, contribuye a diseñar-, sino también su supuesta ahistoricidad al demostrar que "el espacio privado de la mujer es sostén del espacio público porque en él también se funda la nación" (Araújo, 1997, p. 96). La ensayista afirma que las escritoras cubanas burlan la ideología patriarcal en sus autobiografías pues al relacionar el yo privado y la historia se insertan en el proyecto nacional, elaboran una imagen alternativa de la nación en cuya construcción participan activamente, desde el espacio doméstico donde habían sido confinadas. Por otra parte, desmonta el mito de la precariedad atribuido a la escritura (autobiográfica) de las cubanas, al demostrar que generalmente la presunta escasez de su literatura ha sido amplificada por actitudes críticas discriminatorias cuyo resultado - deliberado o no- ha sido la eliminación de sus textos de la tradición literaria cubana. 
En los seis ensayos que conforman la segunda parte del volumen - "Lecturas feministas del canon cubano" - la autora analiza una zona de la producción literaria de las escritoras cubanas. Estudia Espatolino de Gertrudis Gómez de Avellaneda; la novelística de Ofelia Rodríguez Acosta; el pensamiento de Camila Henríquez Ureña; la cuentística femenina de la Revolución y, por último, la tensión entre eros y emancipación, identificado como el conflicto medular del feminismo cubano.

En cada uno de los ensayos se derrumban uno tras otro los prejuicios androcéntricos los cuales han provocado la exclusión o escaso reconocimiento de las obras de las escritoras cubanas, aún cuando emulan en calidad literaria con la de sus contemporáneos. En el ensayo dedicado al Espatolino de Gertrudis Gómez de Avellaneda la autora comienza impugnando la tradición crítica que la precede, al expresar: "La obra de Gertrudis Gómez de Avellaneda [...] suele leerse casi siempre al margen de las discusiones culturales y políticas de su época [...] sus textos narrativos son siempre ponderados casi únicamente por sus virtudes literarias" (Capote, 2008, p. 89; el subrayado es nuestro). Propone, esta vez, una lectura 'diferente', una lectura desmitificadora, — "desde otra perspectiva”, nos dice-. Es decir, una lectura que aborde "las relaciones entre Cuba y España, a pesar de la aparente banalidad de [la] anécdota [de la novela]" (Capote, 2008, p. 89). El ensayo evidencia el agotamiento interpretativo de la crítica literaria androcéntrica la cual realiza, invariablemente, la misma lectura de las obras de las escritoras para arribar a la misma conclusión en torno a su ahistoricidad ${ }^{22}$. Una vez más, la autora reestablece los diálogos de la literatura de las escritoras con la Historia y nos revela las limitaciones de la crítica literaria patriarcal para advertir la tipicidad de tales diálogos.

Los trabajos dedicados a la cuentística escrita y publicada por las escritoras en la isla durante la primera década revolucionaria tienen una importancia capital dentro del volumen, pues en ellos la autora examina las obras y su contexto, a la par que discute abiertamente con la tradición crítica cubana. En "Cuba, años sesenta. Cuentística femenina y canon literario" la ensayista exhuma un corpus narrativo, hasta entonces sepultado por el discurso crítico dominante el cual, afirma, visibilizó y potenció en el perío- do una narrativa de tendencia realista, cultivada mayoritariamente por autores - posteriormente reconocida como 'literatura de la violencia'. La exacerbación de posturas androcéntricas en la crítica literaria cubana de la etapa tuvo consecuencias negativas. Entre otras, la distorsión de la realidad literaria. Asimismo, la "continua negación de la diversidad", y la invisibilización de otras "vertientes poderosísimas en la narrativa cubana" del período, como lo fantástico, lo lírico y lo imaginativo. La literatura de las escritoras, cercana a estas formas menos privilegiadas por la crítica literaria dominante, padeció un ocultamiento, similar a la de otros autores ${ }^{23}$, resultando más visibilizada la de autoras que se adhirieron a las pautas del realismo (como Dora Alonso). La investigadora refuta la precariedad adjudicada a la narrativa de las escritoras durante la década del sesenta al revelar que — una vez más - hubo un "desnivel entre lo que dice la crítica y la realidad editorial" pues "las escritoras estaban ahí — sus libros aún están aquí- pero [...] para muchos eran invisibles" (Capote Cruz, 2008, p. 135):

[los] libros [de las autoras] están ausentes de todos o casi todos los balances, y si, unos años más tarde, se habla de literatura de mujeres será solo para constatar una ausencia que no es más que el espejismo complaciente de una crítica androcéntrica, cuando no el resultado de esa práctica de silenciamiento permanente [...] tanto se las ignoró, que la crítica dominante terminó por olvidarlas (Capote Cruz, 2008, pp. 134-135; p. 145).

En este ensayo, además, la autora desmonta el mito acerca de la ahistoricidad atribuida a la literatura de las escritoras. Considera que la crítica literaria cubana de la época eliminó - deliberadamente o no- su narrativa de la historia literaria de esta primera etapa revolucionaria, basándose en "la ausencia de un compromiso evidente y explícito [que] parecía invalidar sus libros para formar parte de la literatura prefigurada por una crítica cegada por sus propias expectativas" (Capote Cruz, 2008, p. 146). Los textos narrativos de las autoras no 'reflejaban' los acontecimientos históricos de la nación, de la misma manera en que lo hacía la mayor parte de la literatura 'realista', 'explícita', 'comprometida' 'de la violencia' visibilizada por la crítica literaria patriarcal y considerada la literatura. Los relatos de las narradoras - "sobre todo intimistas, 
en los cuales la experiencia revolucionaria inmediata no aparecía" (146) — "humanizaban" los temas históricos. Esta visión de la historia como telón de fondo de la trama explorada por las escritoras en los sesenta, señala la autora, será evaluada al tiempo que valorada de forma positiva por el discurso crítico androcéntrico dos décadas después, solo cuando comienza a ser utilizada como recurso por los autores. Durante siglos, la crítica patriarcal ha demostrado la ductilidad de su escala de valores, la cual se reajusta siempre que sea necesario para fundamentar la inferioridad de la literatura de las autoras y, con ella, su eliminación/exclusión.

El volumen es una gran interrogante acerca de cómo se ejerce el poder en el reducido espacio del texto literario. En él se exploran las relaciones entre género, poder y nación: "El problema del género sexual es también un problema de acceso y empleo del poder", nos recuerda la autora. De ahí, la necesaria comprensión del asunto: quien detenta el poder es, a fin de cuentas, quien determina la representación. El androcentrismo crítico e historiográfico, (pre)dominante (en) nuestra tradición literaria, ha desterrado históricamente la creación de las escritoras cubanas, y con ella, su visión del mundo, de la historia, de la cultura, etc. Al restablecer la presencia de las escritoras y sus obras en el discurso literario nacional, la autora no solo amplía nuestra visión de la historia literaria, sino de nuestra historia nacional. El discurso literario de nuestras escritoras es una fuerza tan desestabilizadora como descentralizadora que, desde los bordes/ los márgenes, atomiza la imagen homogénea y monolítica de la nación cubana, construida por el discurso crítico literario dominante/hegemónico/androcéntrico y patriarcal. El resultado es la construcción de una imagen heterogénea, dialógica y dinámica de la nación cubana.

\section{Conclusiones}

La impronta de las teorizaciones sobre el género en el campo cultural y en el ámbito académico cubanos en torno a los años ochenta produjo una renovación sin precedentes en las ciencias sociales de la isla y, particularmente, en los llamados estudios literarios donde se potenció una actitud revisionista. El renacimiento de una crítica literaria, que reconocía la igualdad creativa de las escritoras, durante la década del noventa transformó radicalmente nuestra visión de la historia literaria y nacional. Las ensayistas y críticas cubanas que abrazaron esta perspectiva de análisis y teoría de la lectura - en particular, las estudiadas- construyeron un escenario más inclusivo y justo para las mujeres, escritoras o no, al desarticular las estrategias de ocultamiento y el sustrato discriminatorio predominantes en buena parte de los estudios literarios tradicionales cubanos. En sus textos desmontaron los principales mitos construidos por el discurso dominante sobre la literatura de las autoras - precariedad, ahistoricidad, e inferioridad-, a la par que demostraron la sinrazón de una praxis que había garantizado durante siglos su eliminación parcial o total de la tradición literaria cubana. Por supuesto, aniquilar tales mitos, elaborados para custodiar la ideología y los intereses de poderosos grupos (literarios, políticos, religiosos y/o económicos), sostenidos por esa tradición crítica de largo arraigo en nuestro campo cultural, no ha resultado tarea fácil, ni expedita, ni terminada. Tampoco lo ha sido (re)construir, sobre esas ruinas, la tradición literaria de las escritoras, e insertarla en el natural devenir de la historia y los acontecimientos nacionales.

A las escritoras de la isla les ha costado imponer su voz en la lírica y en la narrativa, cuanto más en la reflexión literaria, tradicionalmente reservada a los autores. El empoderamiento de sus voces en el ensayo y la crítica literaria contemporáneos resulta una cuestión fundamental para minar definitivamente la estructura monolítica del patriarcado.

La crítica literaria cubana genéricamente marcada se distingue por sus valores intrínsecos, criterios propios e independientes, elevado valor contestatario y rigor científico. Su existencia demuestra la voluntad de los estudios literarios contemporáneos en la isla por intervenir en la conformación de una identidad nacional que contemple los discursos literarios de todos los sujetos, destruyendo el mito construido por la crítica dominante sobre la existencia de un sujeto nacional unitario. Su presencia en el campo intelectual de la isla da fe de las tensiones propias y naturales de una comunidad intelectual inquieta como la cubana. A pesar de ello, esta crítica ha sido menos que atendida como conjunto. En un contexto complejo como este, la contribución del presente trabajo puede considerarse menor y podríamos resumirla en un refrán muy popular entre nosotros: "Poner el parche, antes 
de que salga el hueco". Anticiparse. La experiencia obtenida del pasado demuestra la desmemoria de la crítica androcéntrica, cuando se trata de (re)presentar la literatura, así como la visión de las escritoras en la tradición literaria nacional. Los estudios literarios cubanos no pueden retroceder en las conquistas logradas. Tienen el deber de permanecer alertas tanto ante el florecimiento como ante la exacerbación de posturas androcéntricas y/o patriarcales acendradas hoy, lamentablemente, en algunos espacios de nuestro campo político y cultural.

\section{Bibliografía Principal}

Araújo, N. (1995). Literatura femenina, feminismo y crítica literaria feminista en Cuba. En Letras Femeninas, 24(1-2), 165-71.

Araújo, N. (1996). La escritura femenina y la crítica feminista en el Caribe: otro espacio de la identidad. En M. Yáñez y M. Bobes (Eds.). Estatuas de sal. Cuentistas cubanas contemporáneas (pp. 373-384). La Habana: Ediciones Unión.

Araújo, N. (1997). El alfiler y la mariposa: género, voz y escritura en Cuba y el Caribe. La Habana: Letras Cubanas.

Araújo, N. (1999). El espacio otro en la escritura de las (novísimas) narradoras cubanas. Temas, (16-17), pp. 212-13.

Araújo, N. (2003a). Diálogos en el umbral. Santiago de Cuba: Editorial Oriente.

Araújo, N. (2003b). La huella y el tiempo. La Habana: Letras Cubanas.

Araújo, N. (2007). Más allá de un cuarto propio: once novelas en pugna en el siglo XXI. La Gaceta de Cuba, (2), 3-5.

Campuzano, L. (1996). La mujer en la narrativa de la Revolución: ponencia sobre una carencia. En M. Yáñez y M. Bobes (Eds.). Estatuas de sal. Cuentistas cubanas contemporáneas. (pp. 351-71). La Habana: Ediciones Unión.

Campuzano, L. (1996). La voz de Cassandra. Para presentar Alguien tiene que llorar de Marilyn Bobes. La Gaceta de Cuba, (34), pp.52-53.

Campuzano, L. (2004). Las Muchachas de La Habana no tienen temor de Dios: escritoras cubanas siglo XVIII-XIX. La Habana: Ediciones Unión.
Capote Cruz, Z. (1994). Tres ensayos ajenos. La Habana: Letras Cubanas.

Capote Cruz, Z. (2005). Contra el silencio: otra lectura de la obra de Dulce María Loynaz. La Habana: Letras Cubanas.

Capote Cruz, Z. (2008). La nación íntima. La Habana: Ediciones Unión.

Montero Sánchez, S. (1987). Obra poética de Mirta Aguirre. Dinámica de una tradición lírica. La Habana: Editorial Academia.

Montero Sánchez, S. (1989). La narrativa femenina cubana 1923-1958. La Habana: Editorial Academia.

Montero Sánchez, S. y Capote Cruz, Z. (Eds.). (1999). Con el lente oblicuo. Aproximaciones cubanas a los estudios de género. La Habana: Editorial de la Mujer e Instituto de Literatura y Lingüística.

Montero Sánchez, S. (2003). La cara oculta de la identidad nacional. Un análisis a la luz de la poesía romántica. Santiago de Cuba: Editorial Oriente.

Montero Sánchez, S. (2005). La Avellaneda bajo sospecha. La Habana: Letras Cubanas.

Montero Sánchez, S. (2007). Los huecos negros del discurso patriarcal. La Habana: Ciencias Sociales.

Yáñez, M. (2000). Cubanas a capítulo. Selección de ensayos sobre mujeres cubanas y literatura. Santiago de Cuba: Editorial Oriente.

Yáñez, M. (2003) Camila y Camila. La Habana: Ediciones La Memoria/Centro Cultural Pablo de la Torriente Brau.

Yáñez, M. (2012). Cubanas a capítulo. Segunda temporada. La Habana: Letras Cubanas.

\section{Bibliografía Secundaria}

Armengol, J. M. (2002). Literatura y mujeres: la crítica literaria feminista como paradigma de epistemología de resistencia. En S. Caporale Bizzini, O. Fuentes Soriano, C. Mañas Viejo, N. Montesinos Sánchez, M. T. Ruíz Cantero (Eds.). La difusión del conocimiento en los estudios de las mujeres. Dinámicas y estrategias de poder y ciudadanía. (pp. 438-475). Alicante: Centro de Estudios sobre la Mujer. Universidad de Alicante. 
Caballero Wangüemert, M. (2003). Género y literatura hispanoamericana. Feminismo/s, (1), 103-115. Recuperado de http://hdl. handle.net/10045/2864 doi: 10.14198/ fem.2003.1.08

Cuder Domínguez P. (2003). Crítica literaria y políticas de género. Feminismo/s, (1), 73-86. Recuperado de http://hdl.handle. net/10045/2822 doi: 10.14198/fem.2003.1.06

Culler, J. (1984). Sobre la deconstrucción. Madrid, Cátedra.

Díaz Canals, T. (2012). Una habitación propia para las ciencias sociales en Cuba. La perspectiva de género y sus pruebas. Recuperado de http://biblioteca.clacso. edu.ar/

Díaz Canals, T. (2018). Mujer-saber-feminismo. La Habana: Ciencias Sociales.

Eagleton, T. (1999). La función de la crítica. Buenos Aires: Paidós.

Eagleton, T. (1998). Una introducción a la teoría literaria. México, D. F: Fondo de Cultura económica.

Fornet, A. (2008). La crítica bicéfala en el nuevo milenio: Informe de una situación, II. En A. Fornet (Ed.) El otro y sus signos. (pp. 238-253). La Habana: Editorial Oriente.

Fornet, A. (2008). El otro y sus signos. En A. Fornet (Ed.) El otro y sus signos. (pp. 103-145). La Habana: Editorial Oriente.

Franco, J. (1986). Apuntes sobre la crítica feminista y la literatura hispanoamericana. En Hispamérica, XV(45), pp. 31-43.

Franco, J. (1988). Si me permiten hablar: la lucha por el poder interpretativo. En Casa de las Américas, XXIX(171), pp. 88-96.

Franco, J. (1996). Invadir el espacio público: transformar el espacio privado. En J. Franco. Marcar diferencias, cruzar fronteras. (pp. 91-116). Santiago de Chile: Cuarto Propio.

Golubov, N. (2012). La crítica literaria feminista: una introducción práctica. México, D. F: Facultad de Filosofía y Letras, UNAM.
Golubov, N. (2015). Del anonimato a la celebridad literaria: la figura autorial en la teoría literaria feminista. Mundo Nuevo, VIII(16), pp. 29-48.

Güereca Torres, E.R. (2015). Mujeres, conocimiento y poder: Feminismo(s) en México ante las Sociedades de la Información y el Conocimiento. Doctor, (UNAM). Recuperado de csh.ler.uam.mx/uploads/ teacher/cv/25/CV_Dra._Güereca.pdf

Hernández Hormilla, H. (2011). Mujeres en crisis. Aproximaciones a lo femenino en las narradoras cubanas de los noventa. La Habana: Publicaciones Acuario.

Ludmer, J. (1984). Las tretas del débil. En P.E. González y E. Ortega (Eds.) La sartén por el mango. (pp. 47-54). San Juan: Ediciones Huracán.

Moi, T. (1995). Teoría literaria feminista. Madrid: Cátedra.

Moi, T. (2019). No soy una mujer escritora. En A. de T. Ochoa (Ed.). Horizontes teóricos y críticos en torno a la figura autoral contemporánea. (pp. 93-107). México: Schola, Letras Hispánicas, Facultad de Filosofía y Letras, UNAM.

Moreno, H. (1994). Crítica literaria feminista. Debate feminista, IX(5), pp. 107-12. doi: 10.22201/cieg.2594066xe.1994.9.1750

Olivares, C. (1997). Glosario de términos de crítica literaria feminista. México: El Colegio de México/Programa Interdisciplinario de Estudios de la Mujer. doi: $10.2307 /$ j.ctvhn0bdw

Picallo, X. et al. (2014). Teoría y crítica literaria: Algunos problemas e itinerarios teóricometodológicos. Argentina: Ediciones del gato gris.

Pino Reina, Y. (2008). Aproximaciones a los estudios de género en la crítica literaria. Guantánamo: Editorial El Mar y la Montaña.

Pino Reina, Y. (2019). Hilando y deshilando la resistencia. (Pactos no catastróficos entre identidad femenina y poesía). La Habana: Casa de las Américas.

Reis, B. (1998). ¿Dónde están las mujeres? Mester XXVII(1), 141-147. Recuperado de https://escholarship.org/uc/item/4xf60522. 
Santana Fernández de Castro, A. (2019). La seducción del riesgo. Comentarios al ensayo cubano del siglo XXI. Cuadernos Hispanoamericanos. pp. 829-830.

Recuperado de dossier-cuadernoshispanoamericanos-lit.-cubana-2019.pdf.

Showalter, E. (1999). La crítica feminista en el desierto. En M. Fe (Ed.). Otramente: lectura y escritura feministas. (75-99). México: Fondo de Cultura económica, Programa Universitario de Estudios de Género y Facultad de Filosofía y Letras de la UNAM.

Sóñora Soto, I. (2011). Feminismo y género: el debate historiográfico en Cuba. Anuario de Hojas de Warmi, 16. Recuperado de http:// www.ub.edu/SIMS/hojasWarmi/hojas16/ articulos/ivette.pdf

Vallejo, C. (2012). Vasos comunicantes: persistencia, revisión y el nuevo ensayo de mujeres cubanas, 1947 2007. En Revista Iberoamericana, LXXVIII(240), pp. 521-38. doi: 10.5195/ REVIBEROAMER.2012.6918

Vázquez Domínguez, Y. (2016). Limón, limonero... La literatura femenina cubana en el siglo XXI. La Habana: Editorial UH.

Zambrano, M. (1996). A Camila Henríquez Ureña. En J. L. Arcos (Ed.). La Cuba secreta y otros ensayos. (p. 267). Madrid: Endymion.

\section{Notas}

1 Perspectiva de género: "visión científica, analítica y política creada desde el feminismo que permite analizar las complejas y diversas relaciones [de poder] sociales, políticas y culturales" (Lagarde, 1997). Feminismo: "se trata de una postura que propugna la igualdad entre los géneros. Todo lo demás es floritura. La esencia es esa: la igualdad de condiciones, de posibilidades" (Yánez, 2015).

2 Algunos estudios anteriores (Helen Hernández Hormilla, 2008) ofrecen pistas sobre el desarrollo de la crítica literaria escrita desde la perspectiva de género en la isla. Pero, lo cierto es que, en tales casos, esta no ha sido el objeto de las investigaciones.
3 Del latín humus "tierra", "suelo": Agr. y Geol. Conjunto de los compuestos orgánicos presentes en la capa superficial del suelo, procedente de la descomposición de animales y vegetales.

4 Ambas categorías, estrategias de ocultamiento y metodología de la visibilidad, se tomaron de Güereca (2015) y se adaptaron para el análisis literario. Originalmente, la investigadora las utiliza para describir una situación similar en el campo de la Sociología.

5 La labor reflexiva de las ensayistas estudiadas coexiste $\mathrm{y} / \mathrm{o}$ ha estimulado la de otras quienes han abordado distintos aspectos de la creación literaria de las autoras desde esta/u otras perspectivas de análisis, tales como Olga García Yero, Marilyn Bobes, Aida Bahr, Yanetsy Pino Reina, Helen Hernández Hormilla, Yailuma Vázquez, et al.

6 Las críticas de la isla ofrecen pistas sobre tales relaciones en más de uno de sus ensayos y/o entrevistas. Mirta Yáñez (1998) entró en contacto con los estudios de género en un viaje que realizó a México en 1987. En esa época, recuerda la autora, Elena Urrutia la conminó a reparar en tópicos de la crítica literaria feminista. Luisa Campuzano (2004), por su parte, retoma el tema de la literatura femenina inducida por Jean Franco quien en 1988 comprometió a Casa de las Américas con la organización de un congreso sobre el tema "la literatura escrita por mujeres". La propia Elena Urrutia presionó (y ofreció el motivo en 1990) con la colaboración de Mirta Yáñez quien propició su celebración (Campuzano, 2004). A comienzos de los noventa la Casa de las Américas y el PIEM del Colegio de México organizaron el primer congreso celebrado en Cuba sobre literatura escrita por mujeres y en marzo del siguiente año un grupo de la isla viajó a México para celebrar en El Colegio el segundo congreso, esta vez dedicado a la obra de escritoras cubanas y devenido "el primer encuentro consagrado a nuestra literatura femenina" (Campuzano, 2004, p. 213). En ambos casos, como parte de la preparación de los participantes, se desarrollaron en Casa de las Américas sendos talleres. El primero versó sobre pensamiento y crítica literaria feministas y el segundo, sobre literatura escrita por autoras cubanas. Como resultado de estos encuentros cuatro participantes 
recibieron becas del PIEM para cursar la especialidad de posgrado en Estudios de la Mujer durante el período 1992-1993: Zaida Capote, Madelín Cámara, Marta Eugenia Rodríguez y Mayuli Morales. La Dra. Susana Montero también adquirió esta cualificación, pues disfrutó de la beca en una próxima edición. Además, las académicas de la isla mantuvieron estrechos vínculos con ese país, al pertenecer al claustro de profesores de importantes universidades mexicanas, como Nara Araújo, o disfrutar de estancias de investigación en alguna de ellas, como Mirta Yáñez. Otras, por sus responsabilidades en centros de importancia cultural, compartieron espacios de diálogo donde fueron conminadas por colegas mexicanas a desarrollar esta línea dentro de los estudios literarios académicos cubanos (Mirta Yáñez y Luisa Campuzano).

7 Zaida Capote $(2008$; 2013) y Luisa Campuzano (2004) han teorizado sobre el papel desestabilizador de las crisis, al decir que durante ellas se produce un relajamiento de las estructuras hegemónicas del Patriarcado, y un despertar de la conciencia femenina en distintas formas (artísticas, filosóficas, etc.). La primera ha comentado este fenómeno extendidamente en el prólogo que le dedicara a $\mathrm{Mu}$ jeres en crisis, de Helen Hernández Hormilla. Allí afirmó: "Si repasamos la historia, es fácil ver cada momento en que la crisis (económica, social, política), con su complementaria pérdida de gobernabilidad, proveía el escenario perfecto para el lucimiento de la creación femenina" (Capote, en Hernández Hormilla, 2011, p. 15).

8 Luisa Campuzano (2004) explica el contexto histórico donde se desarrollaron estos sucesos particulares de la vida académica cubana.

9 Helen Hernández Hormilla (2011) ofrece una relación más amplia y detallada de las actividades que se gestaron.

${ }^{10}$ El término 'renacer' fue acuñado por Nara Araújo (1997) para referirse a la etapa de esplendor creativo que vivió la crítica literaria feminista cubana durante la década del noventa. Tiene la intención de recordar el desarrollo experimentado por la crítica literaria comprometida con las demandas del feminismo sufragista cultivada en la década del treinta por notables intelectuales cubanas, como Mariblanca Sabas Alomá.
${ }^{11}$ Nueva visión de Dulce María Borrero constituyó el tema de su tesis de doctorado en la Universidad Carolina de Praga.

${ }^{12}$ Los primeros reclamaban el estudio de corpus hasta entonces arbitrariamente desconocidos por la crítica androcéntrica cubana - la narrativa de las autoras del período revolucionario y republicano, respectivamente- mientras el último proponía un modelo de análisis literario que reconocía las peculiares relaciones de la lírica de las escritoras, en particular de la de Mirta Aguirre, con la Historia.

${ }^{13}$ Prestando particular atención a la huella del género en sus obras, Nara Araújo y Luisa Campuzano aportaron una visión desprejuiciada y novedosa sobre determinados aspectos de sus creaciones literarias en «El alfiler y la mariposa» (Araújo 1997), «La huella y el tiempo» (Araújo, 2003), «Últimos textos de una dama: crónicas y memorias de Dulce María Loynaz» (Campuzano, 2004), «1841: dos cubanas en Europa escriben sobre la esclavitud» (ídem), «Ruinas y paisajes de la memoria» (ídem).

${ }^{14}$ Sobre Aurelia Castillo se publicó en el año 2008 el volumen de Mercedes Valdés Estrella: Aurelia Castillo: ética y feminismo.

15 En Cuba, otras escritoras han publicado atendibles ensayos y crítica literaria sobre el tema literatura y mujeres, utilizando los avances teórico-metodológicos proveniente de los estudios de género. Entre otras, debemos mencionar Mujeres en Crisis (2011), de Helen Hernández Hormilla; Limón, limonero... (2016), de Yailuma Vázquez e Hilando y deshilando. Pactos no catastróficos entre poesía y mujeres (2018) de Yanetsy Pino Reina, ganador del Premio Literario Casa de las Américas. Nuestro trabajo pretende incentivar el interés de otros investigadores y estudiosos por el ensayo y la crítica literaria de las autoras cubanas contemporáneas. También son un pendiente para los estudios literarios cubanos (y para la autora de estas páginas) la obra reflexiva de algunas escritoras cubanas donde la coordenada de género se combina con las de raza y/o clase para analizar diversos aspectos de nuestra cultura: Zuleika Román, Nancy Morejón, Caridad Atencio, entre otras.

${ }^{16}$ En el corpus estudiado el enfoque de género coexiste con otras teorías y metodologías: 
neohistoricismo, postestructuralismo, deconstruccionismo, marxismo, et al. Sin embargo, no es nuestro objetivo en estos momentos ofrecer una caracterización del mismo, atendiendo a sus filiaciones con otras teorías literarias, aunque creemos imprescindible descubrir en acercamientos futuros tales diálogos en aras de ofrecer un estudio cualitativo más completo.

${ }^{17}$ Cubanas a capítulo (2000) /Cubanas a capítulo. Segunda temporada (2012) y La nación íntima (2008), de Mirta Yáñez y Zaida Capote, respectivamente.

${ }^{18}$ Las ideas desarrolladas en este acápite forman parte de la ponencia "Mirta Yáñez, también ensayista y crítica" en el Coloquio Internacional "Expectativas, logros y desengaños del nuevo milenio en la historia y la cultura de mujeres latinoamericanas y caribeñas", celebrado del 18 al 22 de febrero de 2019, organizado por el PEM, Casa de las Américas.

${ }^{19}$ Mirta Yáñez, poetisa, narradora, crítica y ensayista, profesora, investigadora y promotora de la literatura de las escritoras cubanas. Una bibliografía de los estudios de género en Cuba no podría prescindir de su obra reflexiva, especialmente de la reunida en los volúmenes Cubanas a capítulo. Selección de ensayos sobre mujeres cubanas y literatura (2000) y Cubanas a capítulo. Segunda temporada (2012) donde ha recopilado una parte considerable de sus ensayos y su crítica literaria, publicada previamente en forma de prólogos, ensayos críticos y/o entrevistas.
${ }^{20}$ Los prólogos de Susana Montero Sánchez (2000) y Helen Hernández Hormilla (2012), dedicados a introducir los respectivos volúmenes, así como el trabajo de Catharina Vallejo (2012) sobre el ensayo de académicas cubanas, son antecedentes ineludibles de estos comentarios.

${ }^{21}$ Zaida Capote Cruz (1967). Ensayista, investigadora y crítica literaria. Los estudios literarios feministas cubanos no pueden esbozarse sin contemplar su obra reflexiva, especialmente la contenida en Contra el silencio. Otra lectura de la obra de Dulce María Loynaz (2005) y La nación íntima (2008).

${ }^{22}$ Esta idea ha sido elaborada, a partir de la expresada por Ambrosio Fornet (2011) para referirse a una teoría de la lectura ahistórica, la cual está destinada a leer la misma obra, no porque la obra sea siempre la misma (lo cual también pudiera suceder), sino porque realiza invariablemente la misma lectura.

${ }^{23}$ La autora ha expresado que sería un error restringir el análisis de este proceso de invisibilización de la literatura de las autoras al tema de género, puesto que el asunto es aún más complejo y, por ello mismo, debe estudiarse desde varias perspectivas de análisis para explicar el fenómeno. 